\section{Comparison of Intra-Peritoneal Instillation of Bupivacaine and Morphine Hydrochloride versus Bupivacaine and Magnesium Sulfate for Post-Operative Pain Relief after Laparoscopic Cholecystectomy, A Randomized Double-Blind Comparison Study}

\section{Abstract}

Background: Surgical and laparoscopic techniques are two different methods for the removal of gall bladder. Today, laparoscopic cholecystectomy is a preferred method for short-term hospitalization and early return to function related to minimal invasive surgical technique. However, patients still complain of significant postoperative pain, secondary inflammation of the diaphragm and the nociceptive genus of the annoying membrane's peritoneum.

Multimodal analgesia is necessary for managing pain after laparoscopic cholecystectomy. Magnesium sulfate is a new emerging medication for the management of acute pain. There are no previous reports to compare the analgesic effect of intraperitoneal instillation of bupivacaine plus morphine hydrochloride and bupivacaine plus magnesium sulfate for postoperative pain after laparoscopic cholecystectomy.

Aim: The purpose of this study is to compare the analgesic effect of intraperitoneal instillation of bupivacaine plus morphine hydrochloride versus bupivacaine plus magnesium sulfate in patients undergoing laparoscopic cholecystectomy under general anesthesia for better pain relief and less opioid consumption during the first 24 hours.

Methods: Following the approval of the Institutional Review Board of An-Najah National University and written informed consent from patients undergoing laparoscopic cholecystectomy, hundred patients between 18 and 60 years old, American Society of Anesthesiologist (ASA) Grades I and II, were randomized to one of the following groups by the sealed envelope: (Mo group) $(n=50)$ receiving intraperitoneal instillation of $30 \mathrm{ml} 0.25 \%$ bupivacaine and $3 \mathrm{mg}$ morphine and ( $M g$ group) $(n=50)$ receiving intraperitoneal instillation of $0.25 \%$ bupivacaine plus $50 \mathrm{mg} / \mathrm{kg}$ magnesium sulfate to a total volume of $30 \mathrm{ml}$. Medications were given after peritoneal wash and suctioning through intraperitoneal instillation. A drug solution is prepared by a doctor who does not participate in the study. All patients received the same anesthesia method, general anesthesia was administered.

The induction protocol was standard for all patients. Patients were monitored for electrocardiogram (ECG), heart rate, blood oxygenation $\left(\mathrm{SpO}_{2} \%\right)$ and noninvasive blood pressure (NIBP). Postoperative pain was evaluated using visual analog scale (pain score of $0-10$ ). The participants were evaluated for 24 hours after the operation with the registration of abdominal pain. The postoperative pain outcome was reported at 0 and $30 \mathrm{~min}, 1,4,8,12,16$ and 24 hours. The cut-off value for VAS is 4 for indication of rescue medication. At VAS $\geq 4$, rescue analgesics were administered on request ( $20 \mathrm{mg}$ of pethidine) intravenously in Post Anesthetic Care Unit (PACU) and 50 mg intramuscularly in the surgical ward.
Wael Sadaqa*, Obaida Weld Ali, Aida Alkaissi, Khaled Demyati, Abdelkarim Barqawi, Muhammad Jaber, Muhammad Milhim, Arab Ramadan, lyad Maqbool and Waleed Rimawi

An-Najah National University, Nablus, Palestinian Territory, Israel

Corresponding author: Wael Sadaqa

w.sadaqa@najah.edu

Senior consultant-Anesthesia and intensive care, Head of anesthesia and SICU, An-Najah National University, Nablus, Palestinian Territory, Israel.

Tel: 00970599782246

Citation: Sadaqa W, Ali OW, Alkaissi A, Demyati K, Barqawi A, et al. (2018) Comparison of Intra-Peritoneal Instillation of Bupivacaine and Morphine Hydrochloride versus Bupivacaine and Magnesium Sulfate for Post-Operative Pain Relief after Laparoscopic Cholecystectomy, A Randomized Double-Blind Comparison Study. Int J Anesth Pain Med. Vol.4 No.1:6 
Results: Patients' characteristics of age, gender and BMI were comparable in the two groups. There was no significant difference between the groups regarding the duration of the surgery. The demographic parameters (age, gender and BMI) have no effect on the mean of VAS ( $p$ value $>0.05$ ). There are significant differences

between Mo and Mg groups in the total VAS score ( $p$ value<0.05). In the Mo group, the mean of total VAS (2.09) was significantly lower than the mean of total VAS in the Mg group (2.71); which means that patients in the Mo group had significantly less intensity of pain than patients in the $\mathrm{Mg}$ group $(\mathrm{p}=0.006)$.

There is a significant difference between the number (percent) of patients complaining of moderate to severe postoperative pain in Mo group 15/50 (30\%) compared to $\mathrm{Mg}$ group 25/50 (50\%) ( $p=0.0423)$. When estimating the size of the treatment effect of morphine hydrochloride plus bupivacaine, found that the relative risk reduction of moderate to severe pain postoperatively is 0.40 . There is also a significant difference between the number (percent) of patients complained of drowsiness in Mo Group 7/50 (14\%) compared to Mg group 18/50 $(36 \%)(p=0.0115)$. There are no significant differences between the two study groups regarding nausea, vomiting, dizziness and urinary retention.

Patients in Mo group consume less rescue analgesic dose $M( \pm S D)$ (64.29 $\mathrm{mg}+22.04)$ compared to patients in $\mathrm{Mg}$ group $\mathrm{M}( \pm \mathrm{SD})(74.40 \mathrm{mg}+25.67)$ without significant relationship between both doses ( $p$-value=0.163). Blood pressure, heart rate and oxygen saturation were examined as hemodynamic parameters. The result showed that no significant relationship between these parameters and VAS ( $p$-value $>0.05$ ).

Conclusion: Intraperitoneal instillation of combination of bupivacaine with morphine hydrochloride is superior to bupivacaine plus magnesium sulfate to reduce the intensity and incidence of postoperative pain in patients undergoing laparoscopic cholecystectomy surgery without significant increase of side effects. This peripheral effect of opioid provides a new approach to pain relief that can have major clinical benefits.

Recommendation: Based on the results of this study, it is recommended to consider the intraperitoneal instillation of morphine hydrochloride with bupivacaine as a standard application for laparoscopic cholecystectomy surgery to reduce postoperative pain.

Keywords: Bupivacaine; Intra-peritoneal instillation; Laparoscopic cholecystectomy; Magnesium sulphate; Morphine hydrochloride; Rescue analgesia; Post-operative pain.

Received: February 26, 2018; Accepted: April 20, 2018; Published: April 30, 2018

\section{Introduction}

A symptomatic gallstone disease is one of the prevailing problems seen in clinical practice [1]. Surgical removal of the gall bladder can be done laparoscopic or open cholecystectomy [2]. Laparoscopic cholecystectomy (LC) affords different accomplishment compared to open cholecystectomy, and it is the accepted gallstone treatment approach, as it contributes minimum bowel guidance, culminating in hasty return to function and reduce the length of stay at the hospital [3].

Similar to all surgical procedures, patients have compelling postoperative pain; the patients experience severe abdominal and throat pain at the start of the postoperative period and crave pain relief after laparoscopic surgery [4-8]. Progressive manner to further reduce this pain are the subject of many ongoing studies. Intraoperative and postoperative techniques for diminishing postoperative pain have been expressed [1]. Better control of postoperative pain can benefit L.C. as a procedure for day care and avert further complications. On-going practice for many institutions, including ours, is to release the patient on the first postoperative day [1].

In the United States, over 73 million surgical procedures are executed on patients annually. Up to $75 \%$ of these patients struggle with postoperative pain, which may have a decisive effect 
on rehabilitation time [9]. Acute postoperative pain alleviation is important for patient satisfaction and time for discharge, which will promote results and lower healthcare expenditure [10]. Pain can be visceral due to peritoneal irritability induced by floating carbon dioxide in the abdomen, chest pain due to irritation of diaphragm and lesser oftentimes parietal abdominal pain can evolve when disturb the abdominal wall [11].

Different treatments have been proposed to treat pain after laparoscopy. The note of peritoneal inflammation after carbon dioxide, pneumoperitoneum, contributes to a legitimate framework for the practice of non-steroidal anti-inflammatory drugs (NSAIDs) [12-17]. Nonetheless, treatment of post laparoscopic pain with NSAID revenues questionable outcomes. Presently, the common treatment for acute postoperative pain is the practice of systemic opioids [10]. Opioids are not apart from complications [18]. Drowsiness, nausea, vomiting, urinary retention are all side effects of opioids. These side effects can preeminent to longer stay and deprived patient outcomes [18].

Alternately, the handling of IV-acetaminophen is postoperatively expanding $[19,20]$. This practice restraints post-operative usage of opioids and lessens opioid produced side effects [21]. Bringing up rear, the usage of IV-acetaminophen should be utilized with discretion in some patients, such as hypovolemia pertinent to dehydration or blood loss, chronic malnutrition and severe renal deterioration. Further, IV acetaminophen is inconsistent in patients with severe hepatic devastation $[19,20]$.

The performance of injecting local anesthetics into the different layers of the surgical section (sore) is a familiar practice in general anesthesia of surgical cases [22]. Operations with local anesthetics have continued to increase in popularity since the mid 1990's [23]. It is legitimately inexpensive, technically uncomplicated, and may probably diminish postoperative embarrassment [24]. Perioperative localization anesthesia (LIA) is one of the ultimate techniques for accomplish these scopes [25-27]. LIA to the surgery site is a simple way and has demonstrated an immense impact on the abdomen, chest and plastic surgical setting. Literally, it is an extensively used analgesic technique in the last years. In this technique, a solution is used that encompasses long-term local anesthesia in combination with opioids, NSAIDs or steroids $[27,28]$.The effects of LIA may differ depending on the type of surgical procedure, type and dosage of local anesthesia, ancillary addition to local anesthesia, injection in the incision or whole wound [29].

There are two fundamental methods of local anesthetic wound setting: The first is a precautionary model that administers anesthesia pre-operatively. The second model administers anesthetics immediately before surgical termination at the end of surgery [10]. Currently, peripheral usage of local anesthetics for postoperative pain administration has become a favoured method of laparoscopic surgery. Many reports are accessible on the impact of intraperitoneal local anesthesia for pain alleviation after laparoscopic surgery. Combinations of intraperitoneal bupivacaine with morphine have been studied formerly [30]. The results were demonstrated that patients with combinations of intraperitoneal bupivacaine and morphine may promote pain relief and fewer opioid consumption during the first 24 hours, compared with only the bupivacaine group.

Combinations of intraperitoneal bupivacaine with magnesium sulfate have been examined for the treatment of acute pain in L.C. [31]. The results exhibited that intraperitoneal instillation of bupivacaine plus magnesium sulfate grants excellent analgesia in the immediate postoperative period after laparoscopic surgery. There are no prior reports to compare the analgesic effect of intraperitoneal instillation of bupivacaine plus morphine hydrochloride and bupivacaine plus magnesium sulphate for postoperative pain after laparoscopic cholecystectomy. The purpose of this study is therefore to compare the analgesic effect of intraperitoneal instillation of bupivacaine plus morphine hydrochloride versus bupivacaine plus magnesium sulfate to provide effective postoperative pain relief in patients undergoing L.C. under general anesthesia.

\section{Background}

\section{Chronological development of surgical technique of cholecystectomy}

Jean-Louis Petit, inventor of gallbladder surgery in 1733 proposed ousting gallbladder and drainage of the gall bladder, thus creating fistula in patients with empyema which he profitably implemented in 1743 [32]. Marion Simms operated the first cholecystectomy of a 45-year-old woman with obstructive jaundice 1878 [33]. Mouret from France performed the first human L.C. On the day of March 1987, when he concluded a gynecological laparoscopy on a woman who also complained from symptomatic gallstones, he shifted his laparoscope to the sub-hepatic area. When he found a somewhat free and smooth gall bladder, he determined to remove the laparoscopic instead of opening. He implemented the procedure profitably and the patient recovered without complexity [34].

There are three components of pain after laparoscopic surgery:

1. Visceral pain trunks from the expanding of the intraabdominal cavity and peritoneal inflammation.

2. Shoulder pain is the consequence of phrenic nerve irritation precipitated by enduring carbon dioxide in the abdominal cavity.

3. Parietal pain as a result of surgical incision which is lower in intensity by cause of its small size [35].

Pain

Definition of pain: Pain after laparoscopy can be moderate or 
severe for part of patients. Progressively, the nature of pain after laparoscopy diverges significantly from that observed after laparotomy. In fact, laparotomy primarily results in parietal pain (abdominal wall); patients ascribe more of visceral pain after operative laparoscopy [36]. Shoulder pain attributes to diaphragmatic irritability subsequently of carbon dioxide; pneumoperitoneum is a usual postoperative observation after laparoscopy (35\% to 60\%) [14,37].

Visceral pain tales for the greater dislike experienced in the recent postoperative period. Intensity diminishes quickly after the first 24 hours postoperatively. Although visceral pain progresses after L.C. is not impressed by mobilization, cough increments its intensity. Indeed the mobilization test only enforced the contraction of the abdominal muscles and did not comprise the movement of the intra-abdominal viscera. In opposition, cough harvest a brusque displacement of the liver and hence results in stimulation of the inflamed cholecystectomy wound. Parietal pain is lesser intense than visceral pain by cause of the small abdominal cuts and the bordered damage to the abdominal wall. For the same apprehension, and in contrast to pain after laparotomy, parietal pain after L.C. requires intense abdominal muscle contraction to be incremented and consequently aggravated only by cough but not bygone mobilization. Shoulder pain, insignificant during the first postoperative hours, then increases to develop into the main trouble on the second day post-operatively [38].

Shoulder pain that is contingent to the diaphragm's irritation is the major trouble in patients undergoing gynecological laparoscopy. It is reasonable to propose that bupivacaine conducted in the sub-diaphragmatic area blocks nociceptive input engendered in the inflamed diaphragmatic peritoneum. After L.C. Visceral pain is prevalent, while shoulder pain is imperceptible. An anatomic intraperitoneal flow (or flux) advance local anesthesia to the sub-membrane area $[39,40]$ and aside from the cholecystectomy wound. Therefore, pain convinced in this wound is not blocked, although local anesthesia is conducted in its immediate proximity. Correspondingly, local anesthesia after intraperitoneal administration may not accomplish adequate local concentration to block nociceptive entrance from the abdominal wall. Finally, shoulder pain, ignored in early postoperative period, can be actually ignored by patients who, consequently, will not observe any reduction after intraperitoneal bupivacaine [38].

Pathophysiology of post-operative pain: Promptly enlarge gastrointestinal tract can be accompanied with damage of blood vessels, traumatic clench of nerves and discharge of inflammatory mediators. The lengthened exist of shoulder pain $[36,41,42]$ suggest agitation of the phrenic nerve. This pain is most common after laparotomy [43] and both laparotomy and laparoscopy are accompanied with constant pneumoperitoneum, sometimes for 3 days. There is a statistically significant relationship between the width of the gas bubble and pain score [44] and this pain can be diminished by aspiration of the gas under the diaphragm [42] with "active aspiration" is reduplicated suction and manipulation
[45] using a gas discharge or by applying local anesthesia under the diaphragm under direct vision $[46,47]$ or by a sub-frenic catheter [48]. Peritoneal inflammation or the existence of gas is perhaps also the root of the upper abdominal pain after lower abdominal surgery or after diagnostic laparoscopy. This may also ending for a minimum 3 days [41]. The usage of nitrous oxide instead of carbon dioxide for peritoneal insufflation cannot be pledged for the intra-abdominal explosions reported [49], but it negatively reversal the incidence and severity of postoperative pain or nausea and vomiting $[50,51]$.

\section{Pharmacodynamic and pharmacokinetic of the study drugs}

The justification for choosing the intraperitoneal route is to block the visceral afference signal and possibly adjust visceral nociception and give analgesia. Local anesthetics hinder nociception by influencing nerve membrane associated proteins and by hindering the discharge and action of prostaglandins and other agents that animate or stimulate the nociceptors and devote to inflammation [52]. Nonetheless, absorption from large peritoneal surface may happen, which may be another analgesic mechanism [30]. Bupivacaine is preferred in the current study because of its efficiency and long-term efficacy activity. The halflife of bupivacaine is between $5 \mathrm{hrs}$ and $16 \mathrm{hrs}$ [30].

By employing intraperitoneal local anesthesia (IPLA) it may be conceivable to regulate peritoneal and visceral signalling to the brain, by that alleviate the metabolic effect of visceral surgery. There is a barricade of free afferent nerve endings in the abdomen. Systemic penetration of local anesthesia from the abdominal cavity can also play a role in diminished nociception. Local anesthetics have anti-inflammatory impacts and the mechanism of these impacts can be prostaglandin antagonism, hinder of leukocyte migration and lysosomal enzyme discharge [30].

Morphine hydrochloride: Morphine is a definite mu receptor agonist and the most hydrophilic opioid in clinical usage. The hydrophilic quality concludes in reluctant passage athwart membranes like the intestinal mucosa and the blood brain barrier. The analgesic reaction is quiet even if given intravenously. Bioavailability is largely decreased when given orally or rectally and with relevant individual variances [53]. Morphine is metabolized in the liver by unification to morphine 3-and morphine-6glucuronide [54-56]. Metabolites are eliminated through the kidneys $[57,58]$.

Common side effects associated with morphine use include: Gastrointestinal side effects. These include nausea, vomiting, stomach cramps and constipation. Shrink pupils-Morphine can account pupils to compress and emerge pointed in size. Respiratory depression-The breathing mechanism can be depressed due to limited blood oxygen levels. In healthy people, when blood oxygen declines and blood carbon dioxide goes up, respiratory drive increment. However, morphine debilitates this drive in the brain [59]. 
Start doses advance to euphoria but at larger doses unpleasant symptoms such as hallucinations, delirium, dizziness and confusion appear. There may be some headache and memory loss. Biliary colic and consequent severe abdominal pain are common in the overdose of morphine. With high doses, muscle rigidity and abnormal movement of limbs and muscles called myoclonus can confessed [59].

Magnesium sulphate: Magnesium is the fourth most familiar cation in the body. It has relevant physiological roles in enzymatic activation of energy metabolism and protein synthesis [60]. Magnesium has also been demonstrated to have anti-nociceptive effects in animals and human models of chronic pain [61,62]. The analgesic tracts of magnesium are basically regarded to the antagonism of the $\mathrm{N}$-methyl-D-aspartate (NMDA) receptor and the control of calcium influx in cells $[61,63,64]$. This analgesic effect was first demonstrated in humans in 1996 when magnesium was given intravenously during the perioperative period [62]. It has been suggested to reduce post-operative analgesic needs $[65,66]$.

Bupivacain: Bupivacaine is the determined local anesthetic in caudal, epidural and vertebral anesthesia and is most often used clinically to handle with acute and chronic pain [67].

Further to blocking $\mathrm{Na}$ - channels, bupivacaine influences the activity of many other channels, counting NMDA receptors. It is crucial that bupivacaine hinders NMDA receptor-mediated synaptic transmission in spinal dorsal horns, an area gravely involved in centralized sensitization [67]. Rising concentrations of bupivacaine decreased $\mathrm{GluN}_{2}$ subunit channel transparency and $\mathrm{pH}$-independent ways by incrementing the average period of closures and diminishing median time for openings [67].

\section{Aim and Objectives}

The purpose of this study is to compare the analgesic effect of intraperitoneal instillation of bupivacaine plus morphine hydrochloride versus bupivacaine plus magnesium sulfate to provide effective postoperative pain relief in patients undergoing L.C. under general anesthesia.

\section{Problem Statement}

- Postoperative pain is one of the greater prevalent problems after L.C. Diminishing of postoperative pain increases functional recovery, decreased hospitalization and postoperative morbidity.

- There are three sorts of pain after L.C: Incisional, visceral and shoulder pain. The pain is caused by many factors and is a multimodal pathway, so pain relief is important [68].

- The pain of laparoscopic procedures is basically visceral in its origin. Factors that are extensive for this pain may be regarded to surgical procedures, $\mathrm{CO}_{2}$ insufflation and intra-abdominal pressure cultivate during laparoscopic procedure. Higher insufflation pressure should be prevented as they can significantly increment the severity of postoperative pain [68].
- Sub-phrenic and shoulder pain after laparoscopic procedures debut to derive from diaphragmatic and phrenic nerve irritation due to insufflated $\mathrm{CO}_{2}$. This pain contributes to aggravate by ambulation and may end many days after surgery. Remaining insufflating gas can also increment the intensity of post-laparoscopic pain. Accordingly, the abdomen should be actively vented at the end of the laparoscopic procedure [68].

- Opioids are the groundwork of post-operative pain monitoring; high dose opioids have many side effects such as respiratory depression, ileus, nausea and vomiting. Any other way the devaluation of opioid dose would increments the degree of postoperative pain in patients.

- Some complications can be prevented when diminishing postoperative pain in L.C, for example limited respiratory effort and inability to adequately cure secretion, leading to a reduction in functional residual capacity, early airway closure, segment or lobar collapse, retention of secretion which can generate bronchopneumonia [69].

\section{Significance of the Study}

Surgical procedures are accompanied with tissue destruction and the majority of patients treated will experience some degree of pain after surgery. Many patients complain from moderate or severe pain after surgery. Research has demonstrated that poorly handled pain management can have both acute and chronic adverse effects. Peripheral action of opioid especially in inflamed tissue administer support for the existence of peripheral opioid receptors and provides a new accession to pain management that can have major clinical advantages. Yet there is static argument and local anesthesia instillation has not proved to be an ultimate method [70].

Magnesium sulfate is adjuvant that antagonizes calcium similar to the NMDA receptor antagonists $[66,71]$. Magnesium and Bupivacaine award both safe and cheap medicines to decrease postoperative pain and analgesic consumption and have been used as effective adjuvants for postoperative pain handled [72]. Postoperative recovery may be protracted by postoperative pain and complications may happen more periodically [73]. According to our knowledge, no data have been published about the incidence of postoperative pain or the effect of post-operative pain management in Palestine. The ultimate vision is to improve postoperative pain management to the point where pain after surgery can be prevented and surgery becomes "painless".

\section{Literature Review}

Postoperative pain management planning should begin during the preoperative period. There are several studies that deal with the monitoring and control of pain after L.C. and compare the effect of wound setting with marcaine and opioids, such as morphine, as compared to magnesium sulphate for postoperative analgesia [74].

Addition of opioid to local anesthetics results in better 
postoperative analgesia and reduces opioid demand after surgery as described in a study by Chander et al. [75]. The same study shows that unbearable cut pain decreased when adding fentanyl as opioid to bupivacaine and decreased analgesic postoperative consumption [75]. Tverosky et al. [76] determined that wound adjustment provides good postoperative analgesia, which facilitates a fast and even recovery. Local anesthetics are potent long-term and act through several mechanisms including inhibition of the effects of prostaglandins, inhibition of migration of leukocytes and reduce of vascular permeability.

The results of the study conducted by Upadya et al. [77] included a total of 60 patients ASA I and II planned for L.C. included, group I received $2 \mathrm{mg} / \mathrm{kg} 0.5 \%$ bupivacaine as a local intraperitoneal application and group II patients received $1 \mathrm{~g}$ of paracetamol every 6 hours. Postoperatively, patients were assessed for pain using Visual Analog Scale (VAS), Visual Rating Scale (VRS), and Shoulder pain. The total number of patients required to save analgesia (R.A.) and possible side effects was noted, the authors show that intraperitoneal and intra-incisional instillation of $0.5 \%$ bupivacaine gives lower visual analogue scale up to 4 hours. Postoperatively.

On the other hand, Eldaba et al. [78] studied local anesthesia with magnesium sulfate after caesarean section, a total of 120 patients, ASA I-II was recruited for Caesarean section. At the end of the operation, the wound was infiltrated continuously at a rate of $5 \mathrm{ml} / \mathrm{h}$ for 24 hours postoperatively with one of the following solutions: $0.25 \%$ bupivacaine, a mixture of $0.125 \%$ bupivacaine and $5 \%$ magnesium sulfate or normal saline $(0.9 \%)$. Total opioid consumption, VAS in rest and movement, the occurrence of opioid adverse events and signs of ulceration were evaluated during the study period ( 24 hours after surgery). Remaining pain, surgical wound infection, need for additional antibiotic treatment and wound healing failed; and showed that the continuous wound infusion with local anesthesia alone reduced opioid needs by approximately $37 \%$. At the same time, continuous wound infusion with a mixture of local anesthesia and magnesium sulphate reduces opioid demand by approximately $75 \%$ compared to placebo. Opioid-saving effect reduced postoperative nausea and vomiting, sedation and urinary retention.

\section{Research Question}

Is there a preference for a group of drugs on the other, which is intraperitoneal instillation of bupivacaine plus morphine hydrochloride and bupivacaine plus magnesium sulfate to reduce postoperative pain in patients undergoing laparoscopic surgery?

\section{Research Hypothesis}

There is a significant difference at a level of 0.05 related to the intensity of post-operative pain between intraperitoneal instillation of bupivacaine (marcaine ${ }^{\circledR}$ ) plus magnesium sulfate group and bupivacaine (marcaine ${ }^{\circledR}$ ) plus morphine hydrochloride group in patients undergoing laparoscopic surgery.

There is a significant difference at a level of 0.05 related to the consumption of rescue medication that is Pethidine between intraperitoneal instillation of bupivacaine (marcaine ${ }^{\circledR}$ ) plus magnesium sulfate group and bupivacaine (marcaine ${ }^{\circledR}$ ) plus morphine group in patients undergoing laparoscopic surgery.

\section{Study Design}

\section{A prospective, randomized, double blind comparison study:}

- Allocation: Randomized.

- Endpoint Classification: Safety/Efficacy Study.

- Primary Purpose: Observation.

\section{Sites and settings}

The participants were taken from AN- Najah national university Hospital, Nablus, Palestine. AN- Najah national university Hospital was selected due to availability of high quality technologies, which not available in any other hospital in west bank of Palestine, and because of the An- Najah national university Hospital is a central high advance hospital and covers the North region of West bank, Palestine. The other hospital at Istishari Arab hospital in Ramallah city, which is high level of technological progress.

\section{Sample and sampling}

The sample of the study was clients from the settings which are determined, the participants were chosen randomly, after having the permissions to conduct the study and assuring confidentiality.

\section{The inclusion subjects}

- Ages 18 and 60 years

- Male and female

- ASA I-II

\section{The exclusion subjects}

- Patient with hepatic or renal dysfunction

- Use of opioid during $24 \mathrm{hrs}$ prior to the study

- Treatment with steroids prior to surgery.

- Drug or alcohol abuse

- Allergy to any of the study drug,

- Chronic pain syndrome as a result of neurological disease

\section{Sample size calculation}

A formula (i.e. Pocock's sample size formula) is used Sample size was predefined by power analysis depending on the likelihood that the decision rule would lead to the conclusion that the pain occurred in the control group (these data were taken from the previous study) [78] and the incidence of pain in the treatment groups would differ. The error (a) was set to 0.05 which is the risk of making Type I errors, and (b) Power (1-type II error) was set to 0.85 . Minimum standard error $=1$. According to the efficacy analysis, 50 patients were recommended in each group.

A formula (i.e. Pocock's sample size formula) that can be directly applied for comparison of proportions $P_{1}$ and $P_{2}$ in two equally 
sized groups:

$$
n=\frac{\left[P_{1}\left(1-P_{1}\right)+P_{2}\left(1-P_{2}\right)\right]}{\left(P_{1}-P_{2}\right)^{2}}\left(Z_{\alpha / 2}+Z_{\beta}\right)^{2}
$$

Where:

\section{$\mathrm{n}$ : Required sample size}

$P_{1}$ : Estimated proportion of study outcome in the exposed group (i.e. combination therapy) $\left(P_{1}=0.30\right)$.

$\mathrm{P}_{2}$ : Estimated proportion of study outcome in the unexposed group (placebo therapy) $\left(P_{2}=0.70\right)$.

$\alpha$ : Level of statistical significance

$\mathrm{Z}_{\alpha / 2}$ : Represents the desired level of statistical significance (typically 1.96 for $\alpha=0.05$ )

$Z_{\beta}$ : Represents the desired power (typically 0.84 for $80 \%$ power)

$n=\frac{[0.30(1-0.30)+0.70(1-0.70)]}{(0.30-0.70)^{2}}(1.96+0.84)^{2}$

$n=\frac{[0.30(0.70)+0.70(0.30)]}{(0.40)^{2}}(2.8)^{2}$

$n=\frac{[0.21+0.21]}{0.16}(7.84)$

$n=\frac{[0.42]}{0.16}(7.84)$

$\mathrm{n} \approx 50$ patients

Thus, a total of 100 patients (50 for each group) should be targeted for recruitment into the study

\section{Randomization and blindness}

Randomization was done through opaque and well-sealed envelopes. The sequence generation was done with a computer. The number was printed on envelopes and the group was written on the card together with the serial number. When the patients arrived opened envelopes to see the group that would be assigned.

Blindness: Patients, healthcare providers included in patient care, as collected and analyzed data, were not aware of the distribution of the treatment group.

\section{Methods and Intervention Plan}

- A total of 100 patients, ASA I and II between the ages of 18 and 60, planned for laparoscopic surgery were included in a randomized prospective double-blind study after approval by the IRB and written informed consent.

- The study inclusion criteria included the use of opioid for 24 hours. Pre-study, drug or alcohol abuse and allergy to any of the study medications, chronic pain syndrome where pain evaluation was assessed unreliable due to neurological disease or treatment with steroids prior to surgery.

- All patients received the same anesthetic technique. General anesthesia is administered. The induction protocol was standard for all patients. Patients are monitored for electrocardiogram (ECG), heart rate (H.R.), oxygen saturation $\left(\mathrm{Sa} \mathrm{O}_{2}\right.$ ), noninvasive blood pressure (NIBP) and end-tidal $\mathrm{CO}_{2}\left(\mathrm{ETCO}_{2}\right)$. 18-gauge intravenous cannula was inserted into a suitable vein on the dorsum of non-dominant hand. During the intraoperative period.

- All patients receive ring lactate at a rate of $7 \mathrm{ml} / \mathrm{kg} / \mathrm{h}$. The patients are pre-oxygenated at 5 liters $/ \mathrm{min} 100 \% \mathrm{O}_{2}$ for 3 to 5 minutes. Anesthesia is induced by intravenous administration of fentanyl $(2 \mu \mathrm{g} / \mathrm{kg})$, propofol $(2 \mathrm{mg} / \mathrm{kg})$ and to facilitate the endotracheal intubation recuronium (1 $\mathrm{mg} / \mathrm{kg}$ ). Anesthesia is maintained with a mixture of air and oxygen $50 \% / 50 \%$, sevoflurane $1 \%-2 \%$ and recuronium supplementation is recorded. The ventilation is adjusted to maintain ETCO2 between $35 \mathrm{mmHg}$ and $40 \mathrm{mmHg}$. Patients are placed in trendelenburg position during laparoscopy, intra-abdominal pressure maintained between $12 \mathrm{mmHg}$ and $14 \mathrm{mmHg}$.

- Standard laparoscopic cholecystectomy with 4-port technique was performed. All operations were performed by a team of surgeons who have experience of laparoscopic surgery.

- Randomization was done through opaque and well-sealed envelopes. The sequence generation was done with a computer. The number was printed on envelopes and the group was written on the card together with the serial number. When the patients arrived opened envelopes to see the group that would be assigned. A drug solution is prepared by a doctor who did not participate in the study, and drugs are filled in pre-coded syringes and given to the surgeon.

- Patients were also blinded for the administered drug. The drugs were delivered in the same size syringe and the same color by the surgeon. Nurses evaluating patients for parameters in the post-anesthesia Care Unit (PACU) and at the surgical ward are not aware of the treatment where the patient was randomized

- Mo group, $30 \mathrm{ml} \mathrm{0.25 \%} \mathrm{bupivacaine} \mathrm{and} 3 \mathrm{mg}$ morphine intraperitoneal were received at the site of surgery via the navel port with patient in a trendelenburg position (after peritoneal washing and suction).

- $\mathrm{Mg}$ group, $30 \mathrm{ml} 0.25 \%$ bupivacaine was received and 50 $\mathrm{mg} / \mathrm{kg}$ magnesium sulfate was introduced in the same pattern as in the Mo group.

- $\mathrm{Co}_{2}$ was then evacuated from the peritoneal cavity and skin incision was sutured. 


\section{Variable definitions}

\section{Dependent variable}

- Dose of rescue analgesic in PACU and in the surgical ward as continuous variable.

- VAS degree in the PACU as continuous variable.

- VAS degree in the surgical ward as continuous variable.

- Adverse events (nausea, vomiting, drowsiness, dizziness, urine retention).

\section{Independent variable}

- Intra-Peritoneal Instillation of Bupivacaine and Morphine Hydrochloride

- Intra-Peritoneal Instillation Bupivacaine and Magnesium Sulfate

- Age.

- Gender.

- Duration of surgery.

\section{Follow up of the patient}

- Usually the cut off value of VAS is 4 for rescue medication indication. When VAS $\geq 4$, rescue analgesic was administered. Before induction of anesthesia patients are instructed how to use a $10 \mathrm{~cm}$ VAS (VAS-0 with end-point labelled "no pain" and 10 to "worst conceivable pain"). The degree of postoperative pain is assessed at $0,1 / 2,1$, $4,8,12,16,24$ hrs using the VAS score.

- R.A. was administered on request, $20 \mathrm{mg}$ of pethidine intravenously in the recovery room and $50 \mathrm{mg}$ intramuscularly in the ward if needed. The number of patients requiring rescue analgesia was recorded in each group.

- Patients evaluated for 24 hours post-operatively with recording of abdominal pain using the standard $10 \mathrm{~cm}$ VAS. The post-operative pain score reported at 0 and 30 minutes, then at $1,4,8,12,16$ and 24 hours using the VAS score.

- The time of arrival in the post-operative recovery room is defined as zero hr. post-operatively. Postoperatively, A trained nurse assessed pain and analgesic consumption. If VAS is $\geq 4,20 \mathrm{mg}$ pethidine is administered as R.A. until patient felt comfortable or VAS $<3$. All adverse effects including nausea vomiting and dizziness are recorded during 24 hours postoperatively.

- Total dose of pethidine requirement measured and recorded in specified data sheet during next $24 \mathrm{hrs}$.

- Postoperative monitoring included noninvasive BP, HR and pulse and respiration were recorded.

- The following parameters are evaluated in all study groups:
- The incidence and severity of postoperative pain for 24 hrs (the severity of postoperative pain measured at 0. 0.5 , $1,2,4,6,8,12,16$ and $24 \mathrm{hrs}$. postoperatively, using VAS pain score.

(1) Total dose of analgesia.

(2) Postoperative complications (nausea, vomiting, urine retention, drowsiness, dizziness).

(3) Postoperative hemodynamics (HR, BP).

- Nausea is treated with metoclopramide (10 mg) i.v.

\section{Morrow assessment of nausea and emesis}

If the vomiting frequency is twice or higher and/or the patient did his nausea $\geq$ on Likert type scale (0-6), it is an indication to give antiemetic (Pramin ${ }^{\circledR} 10 \mathrm{mg}$ i.v.). Nausea was scored by a Lickerttype scale, which is called MANE (Morrow Assessment of Nausea and Emesis) [79]. This scale (0-6) was used in daily clinical practice on the post anesthetic care unit (PACU) at our hospital. Symptom severity is rated on the scale (0-6) to answer the question "How would you describe your nausea at its worst" from $0=$ none, $1=$ very mild, $2=$ mild, $3=$ moderate, $4=$ severe, $5=$ very severe and, $6=$ intolerable. MANE has been clinically validated and a testretest reliability coefficient has been determined [79].

\section{Rescue analgesia}

Pethidine, like R.A., was administered on request, $20 \mathrm{mg}$ I.V. in PACU and $50 \mathrm{mg}$ I.M. in the surgical ward as needed. The number of patients requiring rescue analgesia was recorded in each group.

\section{Statistical Analysis}

For statistical analysis, SPSS version 20.0 is used. The parametric variables are presented as mean \pm SD or frequency (\%) and analyzed by student t-test; Statistical analysis is performed with an ANOVA test. Non-parametric variables are analyzed by Chi-Square. $\mathrm{P}<0.05$ was considered as statistically significant. Pearson Correlation between Age and total VAS in Mo and $\mathrm{Mg}$ groups was used.

\section{Ethical Consideration}

This study was conducted in accordance with the Helsinki declaration. Individual consent forms were obtained for all participants.

- Institutional Review Board (IRB) approval of An-Najah National University is obtained.

- Consent was obtained from the patient prior to participation.

- Confidentiality and voluntary participation to all participants were insured

- A detailed explanation of the purpose and objectives of the study was given to all patients. 


\section{Results}

The purpose of the current study was to compare intraperitoneal instillation of bupivacaine and morphine hydrochloride versus bupivacaine and magnesium sulfate for postoperative pain relief after L.C. 100 patients, ASA I \& II, 18-60 years old were recruited in the study.

Patient characteristics regarding age, gender and BMI were comparable in the two groups. There was no significant difference between the groups regarding duration of surgery Table 1 . The results in Table 2 show that there are no significant relationships between the age and the total VAS in both study Mo and $\mathrm{Mg}$ groups ( $P$ values $>0.05)$. The Pearson correlation coefficient in Mo group was $(-0.112)$ and $(-0.052)$ in $\mathrm{Mg}$ group. The results in Table $\mathbf{3}$ show that there are no significant differences between Males and Females in the Total VAS score in both study Mo and Mg groups ( $P$ values $>0.05)$. In Mo group, the mean of total VAS was (1.86) for males and (2.18) for females $(p=0.328)$. In Mg group, the mean of total VAS was (2.45) for males and (2.81) for females $(p=0.253)$.

The results in Table 4 show that there are no significant differences between BMI groups in the Total VAS score in both study Mo and Mg groups ( $P$ values $>0.05$ ). In Mo group, the mean of total VAS was (2.38) for BMI group (35-39.9), (2.13) for BMI group (<=24.9), (1.98) for BMI group (25-29.9), (1.83) for BMI group (30-34.9) ( $p=0.738)$. In Mg group, the mean of total VAS was (3.63) for BMI group (35-39.9), (3.06) for BMI group (<=24.9), (2.72) for BMI group (25-29.9), (2.43) for BMI group (30-34.9) $(p=0.167)$.

The results in Table $\mathbf{5}$ show that there are significant differences between Mo and Mg groups in the total VAS score ( $P$ value $<0.05)$. In Mo group, the mean of total VAS was (2.09) which is significantly lower than the mean of total VAS in Mg group (2.71); which means that patients in Mo group significantly had less intensity of pain than patients in $\mathrm{Mg}$ group ( $\mathrm{p}=0.006)$. The results in Table 6 show that there are significant differences between $\mathrm{Mo}$ and $\mathrm{Mg}$ groups in the VAS score only at the first (1/2 hr.) In Mg group, the mean of VAS at (1/2 hr.) was (2.8) which is significantly higher than the mean VAS at (1/2 hr.) in Mo group (1.78) (p=0.016) Figure 1.

The results in Table 7 show that there is no significant difference between $\mathrm{Mo}$ and $\mathrm{Mg}$ groups in the total R.A. ( $\mathrm{P}$ value>0.05). In Mo group, the mean of total R.A. was (64.29) which is not significantly differ from the mean of total R.A.in Mg group (74.40) $(p=0.163)$.

Table 1 Pearson correlation between Age and total VAS.

\begin{tabular}{|c|c|c|}
\hline Age and Total VAS & Mo & Mg \\
\hline Pearson Correlation & -0.112 & -0.052 \\
\hline Sig. (2-tailed) & 0.602 & 0.807 \\
\hline
\end{tabular}

Table 2 Independent samples t test results between gender and total vas.

\begin{tabular}{|c|c|c|c|c|}
\hline Total VAS & \multicolumn{2}{|c}{ Mo } & \multicolumn{2}{c|}{ Mg } \\
Gender & $\mathrm{M}+\mathrm{S} . \mathrm{D}$ & $\mathrm{t}(\mathrm{P}$-value $)$ & $\mathrm{M}+\mathrm{S} . \mathrm{D}$ & $\mathrm{t}(\mathrm{P}$-value $)$ \\
\hline Male & $1.86+0.75$ & $-0.893(0.382)$ & $2.45+0.81$ & \\
\hline Female & $2.18+0.83$ & & $2.81+0.66$ & $-1.172(0.253)$ \\
\hline
\end{tabular}

Table 3 One way anova test results between bmi and total vas.

\begin{tabular}{|c|c|c|c|c|}
\hline Total VAS & \multicolumn{2}{|c}{ Mo } & \multicolumn{2}{c|}{ Mg } \\
\hline BMI & M+S.D & F(P-value) & M+S.D & F(P-value) \\
\hline$<=24.9$ & $2.13+1.94$ & & $3.06+0.44$ & \\
\hline $25-29.9$ & $1.98+0.75$ & & $2.72+0.7$ & \\
\hline $30-34.9$ & $1.83+0.36$ & $0.423(0.738)$ & $2.43+0.53$ & $1.871(0.167)$ \\
\hline $35-39.9$ & $2.38+0.92$ & & $3.63+1.41$ & \\
\hline Total & $2.04+0.79$ & & $2.71+0.72$ & \\
\hline & & & & \\
\hline
\end{tabular}

Table $\mathbf{4}$ Independent samples t test results between type of surgery and total vas.

\begin{tabular}{|c|c|c|c|c|}
\hline Total VAS & \multicolumn{2}{|c}{ Mo } & \multicolumn{2}{c|}{ Mg } \\
\hline Type of Surgery & $\mathrm{M}+\mathrm{S} . \mathrm{D}$ & $\mathrm{t}(\mathrm{P}$-value $)$ & $\mathrm{M}+\mathrm{S} . \mathrm{D}$ & $\mathrm{t}(\mathrm{P}$-value $)$ \\
\hline Elective & $2.11+0.84$ & $0.681(0.503)$ & $2.71+0.76$ & \\
\hline Acute & $1.88+0.63$ & & $2.72+0.62$ & $-0.042(0.967)$ \\
\hline
\end{tabular}

Table $\mathbf{5}$ Independent samples t test results between type of infiltration and total vas.

\begin{tabular}{|c|c|c|}
\hline $\begin{array}{c}\text { Total VAS } \\
\text { Type of infiltration }\end{array}$ & $\mathrm{M}+\mathrm{S} . \mathrm{D}$ & $\mathrm{t}$ (P-value) \\
\hline $\mathrm{Mo}$ & $2.09+0.81$ & $-2.882(0.006)$ \\
\hline $\mathrm{Mg}$ & $2.71+0.71$ & \\
\hline
\end{tabular}

Table 6 Independent samples $t$ test results between type of infiltration and total vas through time.

\begin{tabular}{|c|c|c|c|}
\hline $\begin{array}{c}\text { Type of infiltration } \\
\text { VAS(hr) }\end{array}$ & Mo & Mg & t(P-value) \\
\hline 0 & $3.33+1.58$ & $4.08+1.85$ & $-1.518(0.136)$ \\
\hline $01-F e b$ & $1.78+1.28$ & $2.8+1.53$ & $-2.491(0.016)$ \\
\hline 1 & $1.78+1.57$ & $2.24+1.42$ & $-1.061(0.294)$ \\
\hline 4 & $1.79+1.18$ & $2.56+1.76$ & $-1.789(0.08)$ \\
\hline 8 & $2.48+1.47$ & $3.36+2.1$ & $-1.671(0.102)$ \\
\hline 12 & $2.26+1.89$ & $2.56+1.19$ & $-0.662(0.511)$ \\
\hline 16 & $1.65+1.43$ & $2.48+1.66$ & $-1.841(0.072)$ \\
\hline 24 & $1.33+0.7$ & $1.6+0.76$ & $-1.271(0.21)$ \\
\hline
\end{tabular}

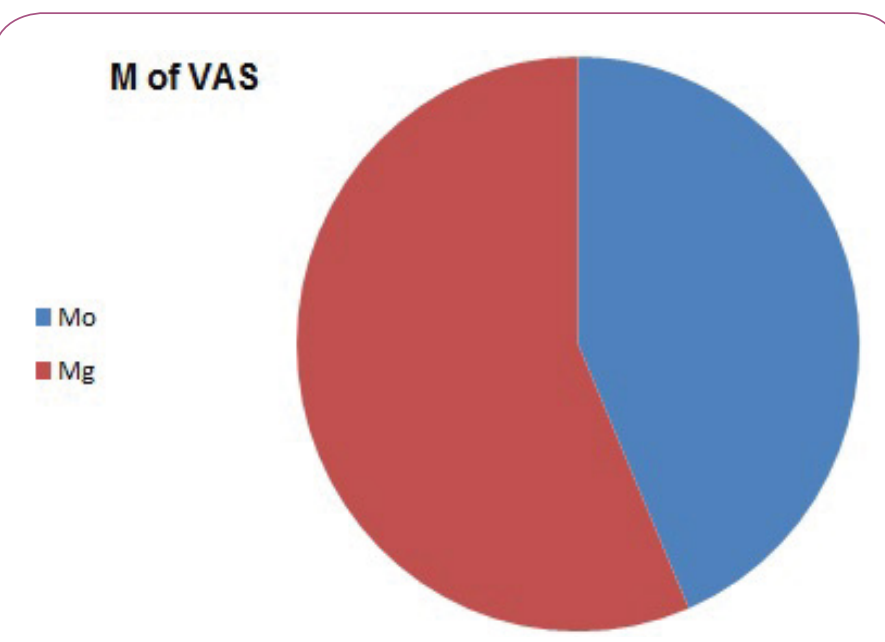

Figure 1 Flow chart detailing the study. 
The results in Table 8 show that there are no significant differences between the number of patients in $\mathrm{Mo}$ and $\mathrm{Mg}$ groups in the Total R.A. at different times $30 \mathrm{~min}, 1,4,8,12$ and 24 hours ( $P$ value $>0.05)$. The number of patients who were requested rescue medication in Mo group at $16 \mathrm{hr} .2(4 \%)$ is significantly less than in Mo group 12(24\%) ( $p=0.0041)$. The results in Table 9 show that there are no significant differences between $\mathrm{Mo}$ and $\mathrm{Mg}$ groups in the SBP through time (all $P$ values $>0.05$ ). In Mo group, the mean of total SBP was (123.34) which is not significantly differ from the mean of total SBP in Mg group (123.45) ( $p=0.971)$. The results in Table 10 show that there are no significant differences between $\mathrm{Mo}$ and $\mathrm{Mg}$ groups in the DBP through time (all $\mathrm{P}$ values $>0.05$ ). In Mo group, the mean of total DBP was (78.04) which is not significantly differ from the mean of total DBP in $\mathrm{Mg}$ group (78.58) ( $p=0.79)$.

The results in Table 11 show that there are no significant differences between $\mathrm{Mo}$ and $\mathrm{Mg}$ groups in the HR through time (all P values>0.05). In Mo group, the mean of total HR was (81.35) which is not significantly differ from the mean of total $\mathrm{HR}$ in $\mathrm{Mg}$ group (83.51) ( $p=0.36)$. The results in Table 12 show that there

Table 7 The mean of total rescue analgesia within 24 hours.

\begin{tabular}{|c|c|c|}
\hline Total rescue analgesia & M+S.D & t(P-value) \\
\hline Type of infiltration & $64.29+22.04$ & $-1.419(0.163)$ \\
\hline Mo & $74.40+25.67$ & \\
\hline
\end{tabular}

Table 8 Frequencies of total rescue analgesia through type of infiltration and time.

\begin{tabular}{|c|c|c|c|}
\hline $\begin{array}{c}\text { Total Rescue } \\
\text { Analgesia (hr) }\end{array}$ & $\begin{array}{c}\text { Value of } \\
\text { Pethidine Dose } \\
(\mathbf{m g})\end{array}$ & $\begin{array}{c}\text { Mo Frequency } \\
\text { no. of patient (\%) }\end{array}$ & $\begin{array}{c}\text { Mg Frequency } \\
\text { no. of patient (\%) }\end{array}$ \\
\hline $1 / 2$ & 20 & 0 & $2(4 \%)$ \\
\hline 1 & 50 & $2(4 \%)$ & $6(12 \%)$ \\
\hline 4 & 50 & $4(8 \%)$ & $10(20 \%)$ \\
\hline 8 & 50 & $16(32 \%)$ & $18(36 \%)$ \\
\hline 12 & 50 & $14(28 \%)$ & $10(20 \%)$ \\
\hline 16 & 50 & $2(4 \%)$ & $12(24 \%)$ \\
\hline 24 & 50 & 0 & 0 \\
\hline
\end{tabular}

Table 9 Independent samples $t$ test results between type of infiltration and total sbp through time.

\begin{tabular}{|c|c|c|c|}
\hline $\begin{array}{c}\text { Hemodynamic } \\
\text { Systolic blood pressure }\end{array}$ & Mo & Mg & t(P-value) \\
\hline 0 & $125.64+13.6$ & $127.12+13.74$ & $-0.383(0.704)$ \\
\hline $1 / 2$ & $124.32+12.96$ & $125.72+10.71$ & $-0.416(0.679)$ \\
\hline 1 & $121.8+11.82$ & $121.72+10.93$ & $0.025(0.98)$ \\
\hline 4 & $124.8+10.32$ & $123.16+11.33$ & $0.535(0.595)$ \\
\hline 8 & $122.96+10.91$ & $124.28+11.47$ & $-0.417(0.679)$ \\
\hline 12 & $122.64+11.28$ & $123.32+9.88$ & $-0.227(0.822)$ \\
\hline 16 & $123+9.93$ & $121.4+11.84$ & $0.518(0.607)$ \\
\hline 24 & $121.56+9.06$ & $120.84+10.98$ & $0.253(0.802)$ \\
\hline Tot & $123.34+10.21$ & $123.45+10.45$ & $-0.036(0.971)$ \\
\hline & & & \\
\hline & & & \\
\hline & & & \\
\hline & & &
\end{tabular}

Table $\mathbf{1 0}$ Independent samples $t$ test results between type of infiltration and total dbp through time.

\begin{tabular}{|c|c|c|c|}
$\begin{array}{c}\text { Hemodynamic Diastolic } \\
\text { blood pressure (hr) }\end{array}$ & Mo & Mg & t(P-value) \\
\hline 0 & $78.72+8.34$ & $80.04+9.34$ & $-0.527(0.601)$ \\
\hline $1 / 2$ & $78.88+7.13$ & $79.48+8.03$ & $-0.28(0.781)$ \\
\hline 1 & $77.28+6.83$ & $77.92+7.99$ & $-0.304(0.762)$ \\
\hline 4 & $78.76+7.15$ & $79.2+8.33$ & $-0.2(0.842)$ \\
\hline 8 & $78.52+7.7$ & $78.64+8.84$ & $-0.051(0.959)$ \\
\hline 12 & $77.6+7.82$ & $78.12+8.25$ & $-0.229(0.82)$ \\
\hline 16 & $77.84+6.16$ & $77.4+9.44$ & $0.195(0.846)$ \\
\hline 24 & $76.68+6.33$ & $77.84+8.71$ & $-0.539(0.593)$ \\
\hline Tot & $78.04+6.52$ & $78.58+7.82$ & $-0.268(0.79)$ \\
\hline
\end{tabular}

Table 11 Independent samples t test results between type of infiltration and total hr through time.

\begin{tabular}{|c|c|c|c|}
\hline $\begin{array}{c}\text { Hemodynamic } \\
\text { Heart Rate }(\mathrm{hr})\end{array}$ & Mo & $\mathrm{mg}$ & $\mathrm{t}$ (P-value) \\
\hline 0 & $82.8+9.62$ & $84.88+10.1$ & $-0.745(0.46)$ \\
\hline $1 / 2$ & $81.88+9.76$ & $82.92+11.78$ & $-0.34(0.735)$ \\
\hline 1 & $80.64+9.7$ & $84.6+9.55$ & $-1.454(0.152)$ \\
\hline 4 & $82.04+7.93$ & $84.2+10.5$ & $-0.82(0.416)$ \\
\hline 4 & $80.08+7.71$ & $82.92+10.69$ & $-1.077(0.287)$ \\
\hline 12 & $81.92+7.69$ & $83.76+9$ & $-0.777(0.441)$ \\
\hline 16 & $81.16+9.81$ & $82.72+9.9$ & $-0.56(0.578)$ \\
\hline 24 & $80.24+8.48$ & $82.08+9.74$ & $-0.712(0.48)$ \\
\hline Tot & $81.35+7.61$ & $83.51+8.91$ & $-0.924(0.36)$ \\
\hline
\end{tabular}

Table 12 Independent samples t test results between type of infiltration and total $\mathrm{O}_{2} \mathrm{~s}$ through time.

\begin{tabular}{|c|c|c|c|}
\hline $\begin{array}{c}\text { Hemodynamic } \\
\mathrm{Sa} \mathrm{O}_{2}\end{array}$ & $\mathrm{Mo}$ & $\mathrm{Mg}$ & $\mathrm{t}$ (P-value) \\
\hline 0 & $97.4+1.71$ & $97.48+2.73$ & $-0.124(0.902)$ \\
\hline $1 / 2$ & $97.24+1.61$ & $97.68+0.99$ & $-1.162(0.251)$ \\
\hline 1 & $98+1.85$ & $97.88+1.2$ & $0.272(0.787)$ \\
\hline 4 & $98+1.71$ & $98.52+1.16$ & $-1.26(0.214)$ \\
\hline 8 & $98.08+1.66$ & $98.56+1.33$ & $-1.131(0.264)$ \\
\hline 12 & $98+1.71$ & $98.16+1.11$ & $-0.393(0.696)$ \\
\hline 16 & $98+2.02$ & $98.08+1.63$ & $-0.154(0.878)$ \\
\hline 24 & $98.08+1.61$ & $98.04+1.21$ & $0.1(0.921)$ \\
\hline Tot & $97.85+1.42$ & $98.05+0.88$ & $-0.597(0.553)$ \\
\hline
\end{tabular}

are no significant differences between $\mathrm{Mo}$ and $\mathrm{Mg}$ groups in the $\mathrm{SpO}_{2}$ through time (all $\mathrm{P}$ values $>0.05$ ). Mo group, the mean of total $\mathrm{SpO}_{2}$ was (97.85) which is not significantly differ from the mean of total $\mathrm{SaO}_{2}$ in $\mathrm{Mg}$ group (98.05) ( $\left.p=0.553\right)$. The results in Table 13 show that there is significant negative relationship between DBP and total VAS in Mg group ( $P$ value $=0.033<0.05)$, the Pearson correlation coefficient was $(-0.428)$. In Mo group, there is no significant relationship. The results also show that there is significant negative relationship between $\mathrm{SaO}_{2}$ saturation and total VAS in Mo group ( $P$ value $=0.009<0.05$ ), the Pearson correlation coefficient was $(-0.518)$. In $\mathrm{mg}$ group, there is no significant relationship. 
From the other hand, the results show that there are no significant relationships between SBP, HR and the Total VAS in both study Mo and Mg groups ( $P$ values>0.05). The results in Table 14 show that there are no significant relationships between Postoperative complications and total R.A. in both study $\mathrm{Mo}$ and $\mathrm{Mg}$ groups (all $P$ values $>0.05$ ). Regarding nausea, in Mo group, the mean of total rescue analgesia was (70) for patients who hadn't nausea and (62.5) for patients who had nausea $(p=0.521)$. In Mg group, the mean of total R.A. was (53.33) for patients who hadn't nausea and (77.27) for patients who had Nausea $(p=0.132)$.

Regarding vomiting, in Mo group, the mean of total R.A. was (61.67) for patients who hadn't vomiting and (67.78) for patients who had vomiting ( $p=0.543)$. In Mg group, the mean of total R.A. was (72.73) for patients who hadn't vomiting and (75.71) for patients who had vomiting $(0.78)$.

Regarding urine retention, in Mo group, the mean of total R.A. was (64.29) for patients who hadn't urine retention and there were no patients who had urine retention ( $p=>0.05)$. In $\mathrm{Mg}$ group, the mean of total R.A. was (74.58) for patients who hadn't urine retention and (70) for patients who had urine retention $(p=0.865)$.

Regarding drowsiness, in Mo group, the mean of total R.A. was (61.43) for patients who hadn't drowsiness and (70) for patients who had drowsiness $(p=0.415)$. In Mg group, the mean of total R.A. was (67.14) for patients who hadn't drowsiness and (77.22) for patients who had drowsiness $(p=0.389)$.

Finally, there were no patients who had dizziness or other postoperative complications in both groups. The results in the Table 15 show that there is a significant difference between the number (percent) of patients complaining of moderate to severe postoperative pain in Mo group 15/50 (30\%) compared to $\mathrm{Mg}$ group $25 / 50(50 \%)(p=0.0423)$. There is also a significant difference between the number (percent) of patients who complained of drowsiness in Mo Group 7/50 (14\%) compared to $18 / 50(36 \%)$ in $\mathrm{Mg}$ group $(\mathrm{p}=0.0115)$. There are no significant differences between the two study groups regarding nausea, vomiting, dizziness and urinary retention Figure 2 . The results of the Table $\mathbf{1 6}$ show that there are no significant relationships

Table 13 Pearson correlation between postoperative hemodynamic variables and total vas.

\begin{tabular}{|c|c|c|c|}
\hline \multirow{2}{*}{ Tot SBP } & Total VAS & Mo & Mg \\
\cline { 2 - 4 } & Pearson Correlation & 0.247 & -0.335 \\
\hline \multirow{2}{*}{ Tot DBP } & Sig. (2-tailed) & 0.245 & 0.101 \\
& Pearson Correlation & 0.236 & -0.428 \\
\cline { 2 - 4 } Tot HR & Sig. (2-tailed) & 0.267 & 0.033 \\
\hline \multirow{2}{*}{ Tot Sa O2 } & Pearson Correlation & -0.025 & 0.055 \\
\cline { 2 - 4 } & Sig. (2-tailed) & 0.908 & 0.792 \\
\hline & Pearson Correlation & -0.518 & -0.204 \\
\hline & Sig. (2-tailed) & 0.009 & 0.328 \\
\hline
\end{tabular}

Table 14 independent samples $t$ test results between postoperative complications and total rescue analgesia.

\begin{tabular}{|c|c|c|c|c|}
\hline \multirow{2}{*}{$\begin{array}{c}\text { Tot } R A \\
\text { variable } \\
(\mathrm{n} 1, \mathrm{n} 2)\end{array}$} & \multicolumn{2}{|c|}{ Mo } & \multicolumn{2}{|c|}{ Mg } \\
\hline & $M(m g)+S . D$ & $t(P$-value $)$ & $M(m g)+S . D$ & $t(P$-value $)$ \\
\hline \multicolumn{5}{|c|}{ nausea } \\
\hline $\mathrm{No}(10,6)$ & $70+35.36$ & \multirow{2}{*}{$0.655(0.521)$} & $53.33+28.87$ & \multirow{2}{*}{$-1.56(0.132)$} \\
\hline Yes $(32,44)$ & $62.5+17.32$ & & $77.27+24.53$ & \\
\hline \multicolumn{5}{|c|}{ vomiting } \\
\hline $\mathrm{No}(24,22)$ & $61.67+28.87$ & \multirow{2}{*}{$-0.619(0.543)$} & $72.73+32.89$ & \multirow{2}{*}{$-0.283(0.78)$} \\
\hline Yes $(18,28)$ & $67.78+6.67$ & & $75.71+19.5$ & \\
\hline \multicolumn{5}{|c|}{ urine retention } \\
\hline $\mathrm{No}(42,48)$ & $64.29+22.04$ & \multirow{2}{*}{----- } & $74.58+26.21$ & \multirow{2}{*}{$0.171(0.865)$} \\
\hline Yes $(0,2)$ & ----- & & $70+0$ & \\
\hline \multicolumn{5}{|c|}{ drowsiness } \\
\hline $\mathrm{No}(28,14)$ & $61.43+26.85$ & \multirow{2}{*}{$-0.834(0.415)$} & $67.14+23.6$ & \multirow{2}{*}{$-0.877(0.389$} \\
\hline Yes $(14,36)$ & $70+0$ & & $77.22+26.53$ & \\
\hline \multicolumn{5}{|c|}{ dizziness } \\
\hline $\mathrm{No}(42,50)$ & $64.29+22.04$ & \multirow{2}{*}{----- } & $74.4+25.67$ & \multirow{2}{*}{---- } \\
\hline Yes $(0,0)$ & ----- & & ----- & \\
\hline \multicolumn{5}{|c|}{ others } \\
\hline $\mathrm{No}(42,50)$ & $64.29+22.04$ & \multirow{2}{*}{----} & $74.4+25.67$ & \multirow{2}{*}{----} \\
\hline Yes $(0,0)$ & ----- & & ----- & \\
\hline
\end{tabular}

Table 15 Independent samples $t$ test results between the abdominal drain left at the end and total vas.

\begin{tabular}{|c|c|c|c|c|}
\hline Total VAS & \multicolumn{2}{|c|}{ Mo } & \multicolumn{2}{|c|}{ Mg } \\
\hline $\begin{array}{l}\text { Abdominal drain } \\
\text { left at the end }\end{array}$ & $M+S . D$ & $t(P$-value $)$ & $M+S . D$ & $t(P$-value $)$ \\
\hline Yes & $2.36+0.77$ & \multirow{2}{*}{$2.597(0.016)$} & $2.79+0.77$ & \multirow{2}{*}{$0.785(0.44)$} \\
\hline No & $1.55+0.61$ & & $2.55+0.57$ & \\
\hline
\end{tabular}

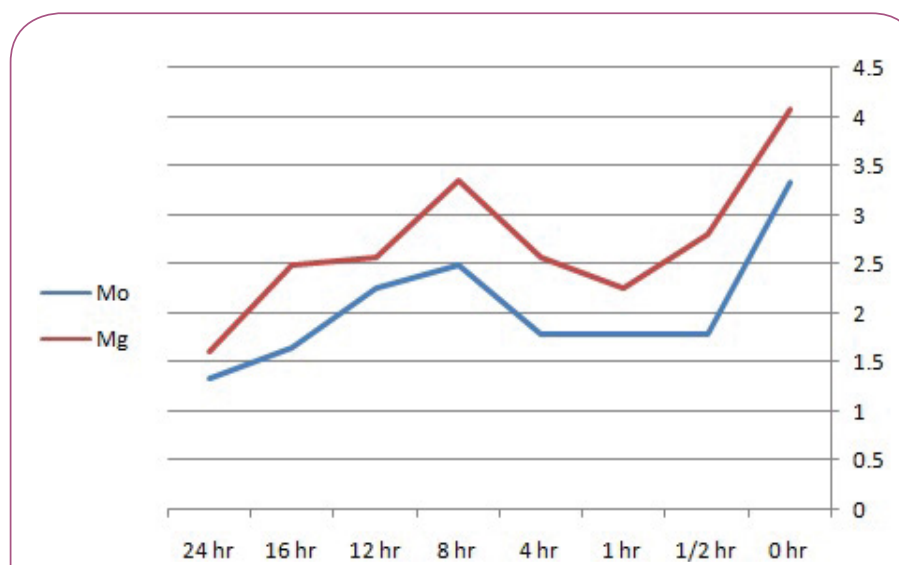

Figure 2 Flow chart detailing the study.

Table 16 Pearson correlation between duration of surgery and total vas.

\begin{tabular}{|c|c|c|c|}
\hline \multirow{2}{*}{ Duration of Surgery } & Total VAS & Mo & Mg \\
\cline { 2 - 4 } & Pearson Correlation & 0.202 & -0.14 \\
\cline { 2 - 4 } & Sig. (2-tailed) & 0.368 & 0.506 \\
\hline
\end{tabular}

between duration of surgery and the total VAS in both study groups ( $P$ values $>0.05$ ). 


\section{Discussion}

\section{Incidence and intensity of post-operative pain}

As the cause of postoperative pain in patients undergoing laparoscopic surgery is multifactorial, multimodal analgesia is necessary to counter postoperative pain. In the current study, at the end of laparoscopic cholecystectomy surgery, 100 patients were randomized to one of the following groups: Mo group receiving intraperitoneal instillation of $30 \mathrm{ml} 0.25 \%$ bupivacaine plus $3 \mathrm{mg}$ morphine hydrochloride and MG group receiving intraperitoneal instillation of $30 \mathrm{ml} 0.25 \%$ bupivacaine plus $50 \mathrm{mg} /$ $\mathrm{kg}$ magnesium sulfate. The results in the current study show that morphine hydrochloride plus bupivacaine significantly reduces the incidence and intensity of postoperative pain compared to magnesium sulfate plus bupivacaine.

The results show that there are significant differences between $\mathrm{Mo}$ and $\mathrm{Mg}$ groups in the total VAS score ( $\mathrm{P}$ value $<0.05)$. In the Mo group, the mean of total VAS (2.09) was significantly lower than the mean of total VAS in the Mg group (2.71); which means that patients in the Mo group significantly had less intensity of pain than patients in the $M g$ group $(p=0.006)$. This means that bupivacaine plus morphine hydrochloride is more effective in reducing the intensity of postoperative pain than magnesium sulfate plus bupivacaine. The rationale for selecting the intraperitoneal pathway is to block the visceral afference signal and potentially modifying visceral nociception. Local anesthetics inhibit nociception by affecting nerve membrane associated proteins and by inhibiting the release and action of prostaglandins and other agents that sensitize or stimulate nociceptors and contribute to inflammation [52]. However, absorption from large peritoneal surface can also occur, which may be a further mechanism of analgesia. We chose bupivacaine for our study because of its long-term effectivity. The half-life of bupivacaine is between 5 hours and 16 hours.

The result of the current study is in accordance with the study by Bena et al. [30] Showed that addition of $3 \mathrm{mg}$ of morphine to $30 \mathrm{ml}$ of $0.25 \%$ bupivacaine further enhanced the effectiveness of intraperitoneal bupivacaine in the reduction of postoperative pain after laparoscopic cholecystectomy surgery [30]. On the other hand, the result of the current study is in violation of Shoebi et al. [80] study that shown when magnesium sulfate is added to bupivacaine, improves intraperitoneal analgesic effect in postoperative period without any unwanted effects [80].

Magnesium sulfate is used in most studies to improve pain relief quality with fewer demands on post-operative analgesics. [72,8183]. Since magnesium reduces intracellular calcium influx and also antagonizes the N-methyl-D-aspartate (NMDA) receptor, which reduces postoperative pain, it is useful for reducing somatic and visceral pain and also reducing the opioid analgesic requirements [84-86].

For the incidence of postoperative pain, there were significantly fewer frequency (percentage) of patients in Mo group 15 (30\%) complaining of moderate to severe pain postoperatively compared to 25 (50\%) patients in the $\mathrm{Mg}$ group ( $p=0.0423)$. This result is consistent with the study performed by Bina et al. [30] As shown, the group of bupivacaine plus morphine hydrochloride had better pain relief than the control group at all-time intervals and this difference was also statistically significant $(P<0.05)[30]$. The study clarifies that morphine hydrochloride with bupivacaine reduces the incidence of postoperative pain. The result of this study complies with the study conducted by Hernandez et al. [35] examined intraperitoneal application of bupivacaine plus morphine for pain relief after laparoscopic surgery and reported that the combination is effective in reducing pain during the first 6 hours [87-90]. In our study when calculating the size of the treatment effect of morphine hydrochloride plus bupivacaine, it was found that the relative risk reduction of moderate to severe pain postoperatively is 0.40 .

On the other hand, a study on the effect of intraperitoneal instillation of opioid showed that morphine was ineffective when given as analgesia. The authors speculated that this may be because the intact peritoneum prevents the entry of hydrophilic morphine molecules and blocks their access to the neural receptors. Inflammation interferes with the peritoneal barrier and, consequently, the access of opioid agonists to the sensory neurons is facilitated to produce only analgesia in swelling tissue [52].

The results of the current study are not in line with Maharjan et al. [31] study conducted in 60 patients undergoing laparoscopic cholecystectomy. Patients were randomized to one of the following groups: the bupivacaine group received intraperitoneal instillation of $30 \mathrm{ml} 0.25 \%$ bupivacaine and magnesium sulfate group receiving intraperitoneal instillation or $0.25 \%$ bupivacaine plus $50 \mathrm{mg} / \mathrm{kg}$ magnesium sulfate to a total volume of $30 \mathrm{ml}$ [9193]. Postoperative pain was evaluated using visual analog scale. The time period for the first analgesia required was noted and rescue analgesics were given as tramadol $50 \mathrm{mg}$ intravenously and as needed. Patients receiving intraperitoneal bupivacaine plus magnesium sulfate at the end of surgery had better pain relief during the first 24 hours. The authors concluded that the combination of bupivacaine and magnesium sulfate in abdominal cavity by laparoscopic surgery gives patients better analgesics and less analgesics during the first 24 hours compared to the bupivacaine group alone.

\section{The requirements for analgesic rescue medication}

The results in the current study show that there is no significant difference between Mo and $\mathrm{Mg}$ groups in Total Rescue Analyze ( $p$-value $>0.05$ ). In the Mo group, the mean of total R.A. was $(64.29 \mathrm{mg})$ which does not differ significantly from the mean of total rescue analgesia in the $\mathrm{Mg}$ group (74.40 $\mathrm{mg}$ ). There is only a significant difference between the Mo and $\mathrm{Mg}$ groups at 16 hours postoperatively in favour of the Mo group. Compared to a previous study by Bina et al. [30] Comparison of the analgesic requirements showed that a number of patients receiving rescue analgesia were significantly lower in bupivacaine and morphine groups compared to bupivacaine and placebo group. 


\section{Adverse effects}

Regarding adverse effects, there were no significant differences between the study groups regarding nausea, vomiting, dizziness, urinary retention and were distributed equally in both groups but there is a significant difference between the groups associated with drowsiness. There are significantly lower number of drowsiness in the Mo group 7/50 (14\%) compared with the $\mathrm{Mg}$ group $18 / 50$ (36\%) ( $p=0.0115)$. The authors of the current study speculated that increased number of patients with drowsiness in the $\mathrm{Mg}$ group could be as a result of the mean (SD) of rescue medication, which is pethidine $74.40 \mathrm{mg} \pm 25.67$ which is higher than in Mo group $64 \mathrm{mg}, 29 \mathrm{mg} \pm 22.04$, This may have caused drowsiness in the $\mathrm{Mg}$ group. The current results are consistent with [30] results regarding adverse effects, only nausea and/or vomiting was present in 10 of 90 patients and was distributed equally in all groups. Bina et al. [30] also explained that there was no itching, excessive sedation or dryness of the bupivacaine plus morphine group. The authors speculated that this could be explained because the dose of morphine used in the intraperitoneal instillation was significantly less to cause systemic side effects. The dose of morphine used was $2 \mathrm{mg}$ morphine added to $0.25 \%$ bupivacaine $30 \mathrm{ml}$.

\section{Hemodynamic parameters}

Regarding hemodynamic parameters, the results in the current study show that there is significant negative correlation between

\section{References}

1 Ahmad A, Faridi S, Siddiqui F, Edhi M, Khan M (2015) Effect of bupivacaine soaked gauze in postoperative pain relief in laparoscopic cholecystectomy: a prospective observational controlled trial in 120 patients. Patient Saf Surg 9: 31.

2 Simpson JP, savarise MT, Moore J (1999) Out patients laparoscopic cholecystectomy: What predicts the need for admission? Am Surg 65: 525-528.

3 Kum CK, Wong CW, Goh MY, Ti TK (1994) Comparative study of pain level and analgesic requirement after laparoscopic and open cholecystectomy. Surg Laparosc Endosc 4: 139-141.

4 Karadeniz U, Erdemli O, Unver S, Yaşıtı H, Ayoğlu H (2000) Intraperitoneal bupivacaine injection and infusion in postoperative pain treatment after laparoscopic cholecystectomy. AGRI 12: 43-48.

5 Memedov C, Menteş O, Şimşek A, Kece C, Yağcı G, et al. (2008) Multiregional local anesthesic administration for the prevention of postoperative pain after laparoscopic cholecystectomy: placebo controlled comparison of ropivacaine and prilocaine. Gulhane Medical Journal 50: 84-90.

6 Ng A, Swami A, Smith G, Robertson G, Lloyd DM (2004) Is intraperitoneal levobupivacaine with epinephrine useful for analgesia following laparoscopic cholecystectomy? A randomized controlled trial. Eur J Anaesthesiol 21: 653-657.

7 Elhakim M, Elkott M, Ali NM, Tahoun HM (2000) Intraperitoneal lidocaine for postoperative pain after laparoscopy. Acta Anastesiol Scand 44: 280-284.

8 Dath D, Park AE (1999) Randomized, controlled trial of bopivacaine
DBP and total VAS in the Mg group ( $\mathrm{P}=0.033)$. In the Mo Group there is no significant relationship. And the results also show that there is a significant negative correlation between $\mathrm{SpO}_{2}$ and total VAS in Mo group ( $P$ value=0.009). In the $\mathrm{Mg}$ group there is no significant relationship. These results were not clinically significant. On the other hand, the results show that there are no significant relationships between both SBP, HR and total VAS in both study $\mathrm{Mo}$ and $\mathrm{Mg}$ groups ( $\mathrm{P}$-values $>0.05$ ). Compared to Bina et al. [30] important parameters such as $\mathrm{HR}$, $\mathrm{BP}$ and $\mathrm{SpO}_{2}$ were identified as important patient comfort indicators as the values correlated well with VAS scores.

\section{Conclusion}

Intraperitoneal instillation of combination of bupivacaine with morphine hydrochloride is superior to bupivacaine plus magnesium sulfate to reduce the intensity and incidence of postoperative pain in patients undergoing laparoscopic cholecystectomy surgery without significant increase of side effects. This peripheral effect of opioid provides a new approach to pain relief that can have major clinical benefits.

\section{Recommendations}

Based on the results of this study, it is recommended to consider the intraperitoneal instillation of morphine hydrochloride with bupivacaine as a standard application for laparoscopic cholecystectomy surgery to reduce postoperative pain.

injection to decrease pain after laparoscopic cholecystectomy. Can J Surg 42: 284-288.

9 Kessler ER, Shah M, Gruschkus SK, Raju A (2013) Cost and quality implications of opioid-based postsurgical pain control using administrative claims data from a large health system: opioid-related adverse events and their impact on clinical and economic outcomes. Pharmacotherapy 33: 383-391.

10 LeBlanc KJ (2014) The Effectiveness of Local Anesthetic Instillation into a Surgical Wound Prior to Surgical Closure. Columbia: University of South Carolina.

11 Wills VL, Hunt DR (2000) Pain after laparoscopic cholecystectomy. Br J Surg 87: 273-284.

12 Comyn DJ (1988) Minimising pain after laparoscopy. Proceedings of the 9th World Congress of Anesthesiologists. Washington.

13 Comfort VK, Code WE, Rooney ME, Yip RW (1992) Naproxen premedication reduces postoperative tubal ligation pain. Can J Anaesth 39: 349-352.

14 Edwards ND, Barclay K, Catling SJ, Martin DG, Morgan RH (1991) Day case laparoscopy: a survey of postoperative pain and an assessment of the value of diclofenac. Anaesthesia 46: 1077-1080.

15 Rosenblum M, Weller RS, Conard PL, Falvey EA, Gross JB (1991) Ibuprofen provides longer lasting analgesia than fentanyl after laparoscopic surgery. Anesth Analg 73: 255-259.

16 Cracker S, Peach M (1992) Preoperative rectal indomethacin for analgesia after laparoscopic sterilisation. Anaesth Intensive Care 20: 337-340.

17 Liu J, Ding Y, White PF, Feinstein R, Shear JM (1993) Effects of 
ketorolac on postoperative analgesia and ventilatory function after laparoscopic cholecystectomy. Anesth Analg 76: 1061-1066.

18 Brennan T J (1999) Postoperative Models of Nociception. ILAR J 40: 129-136.

19 Arslan M, Celep B, Cicek R, Kalender HU, Yilmaz H (2013) Comparing the efficacy of preemptive intravenous paracetamol on the reducing effect of opioid usage in cholecystectomy. J Res Med Sci 18: 172-177.

20 Pasero C, Stannard D (2012) The role of intravenous acetaminophen in acute pain management: a case-illustrated review. Pain Manag Nurs 13: 107-124.

21 Macario A, Royal MA (2011) A literature review of randomized clinical trials of intravenous acetaminophen (paracetamol) for acute postoperative pain. Pain Pract 11: 290-296.

22 Scott NB (2010) Wound Instillation for surgery. Anaesthesia 65: 67-75.

23 Johnson RC, Hedges AR, Morris R, Stamatakis JD (1999) Ideal pain relief following laparoscopic cholecystectomy. Int J ClinPract 53: 16-18.

24 Brower MC, Johnson ME (2003) Adverse effects of local anesthetic Instillation on wound healing. Reg Anesth Pain Med 28: 233-240.

25 Hofstad JK, Winther SB, Rian T, Foss OA, Husby OS, et al. (2015) Perioperative local Instillation anesthesia with ropivacaine has no effect on postoperative pain after total hip arthroplasty. Acta Orthop 86: 654-658.

26 Andersen KV, Jensen MP, Haraldsted V, Søballe K (2007) Reduced hospital stay and narcotic consumption, and improved mobilization with local and intraarticular Instillation after hip arthroplasty: a randomized clinical trial of an intraarticular technique versus epidural infusion in 80 patients. Acta Orthop 78: 180-186.

27 Parvataneni HK, Shah VP, Howard H, Cole N, Ranawat AS, et al. (2007) Controlling pain after total hip and knee arthroplasty using a multimodal protocol with local periarticular injections: a prospective randomized study. J Arthroplasty 22: 33-38.

28 Andersen $L \varnothing$, Kristensen BB, Husted H, Otte KS, Kehlet $H(2008$ ) Local anesthetics after total knee arthroplasty: intraarticular or extraarticular administration? A randomized, double-blind, placebocontrolled study. Acta Orthop 79: 800-805.

29 Shin S, Chung WY, Jeong JJ, Kang SW, Oh YJ (2012) Analgesic efficacy of bilateral superficial cervical plexus block in robot-assisted endoscopic thyroidectomy using a transaxillaryapproach.World J Surg 36: 2831-2837.

30 Bina P, Veena R, Nived K (2013) Randomized double blind trial of intraperitoneal instillation of bupivacaine and morphine for pain relief after laparoscopic gynecological surgeries. Saudi J Anaesth 7: 18-23.

31 Maharjan S, Shrestha S (2012) intraperitoneal magnesium sulfate plus bupivacaine for pain relief after laproscopic cholecystectomy. Journal of Kathmandu Medical College 1: 21-25.

32 Beal JM (1984) Historical perspective of gall stone disease. Surg Gynecol Obstet 158: 181-189.

33 Servetus M (1989) Christianismi Restitutio and Other Writings. Birmingham. The Classics of Medicine Library pp: 115.

34 Mouret $P$ (1991) from the first laparoscopic cholecystectomy to the frontiers of laparoscopic surgery:the prospective futures. Dig Surg 8: 124.

35 Hernández-Palazón J, Tortosa J, de la Rosa VN, Giménez-Viudes J, Ramírez G, et al. (2003) Intraperitoneal application of bupivacaine plus morphine for pain relief after laparoscopic cholecystectomy. Eur J Anaesthesiol 20: 891-896.
36 Joris J, Cigarini I, Legrand M (1992) Metabolic and respiratory changes after cholecystectomy performed via laparotomy or laparoscopy. $\mathrm{Br} J$ Anaesth 69: 341-345.

37 Collins K, Docherty P, Plantevin O (1984) Postoperative morbidity following gynaecological outpatient laparoscopy. A reappraisal of the service. Anaesthesia 39: 819-822.

38 Joris J, Thiry E, Paris P, Weerts J, Lamy M (1995) Pain after Laparoscopic Cholecystectomy: Characteristics and Effect of Intraperitoneal Bupivacaine. Anesth Analg 81: 379-384.

39 Zinsser H, Pryde A (1952) Experimental study of physical factors, including the fibrin formation, influencing the spread of fluids and small particles within and from the peritoneal cavity of the dog. Ann Surg 136: 818-827.

40 Autio V (1964) La propagation de l'infectionintraperitoneale. Etude radiologique. Acta Chir Stand 321: 1-31.

41 Dobbs F, Kumar V, Alexander J, Hull M (1987) Pain after laparoscopy relater to posture and ring versus clip sterilization. $\mathrm{Br} J$ Obstet Gynaecol 94: 262-266.

42 Riedel H, Semm KD (1980) postpelviskopische-(laparoscopische) Schmerzsyndrom. Geburthilfe Frauenheilkunde 40: 635-643.

43 McMahon A, Russell I, Ramsay G, Sunderland G, Baxter J, et al. (1994) Laparoscopic and minilaparotomy cholecystectomy: a randomized trial comparing postoperative pain and pulmonary function. Surgery 115: 533-539.

44 Jackson S, Laurence A, Hill J (1996) Does post-laparoscopy pain related to residual carbon dioxide? Anaesthesia 51: 485-487.

45 Fredman B, Jedeikin R, Olsfanger D, Flor P, Gruzman A (1994) Residual pneumoperitoneum: a cause of postoperative pain after laproscopic cholecystectomy. Anesthesia and Analgesia 79: 152-154.

46 Narchi P (1995) Nouvelles voiesd'Instillation: injections intraperitoneales. Cahiers d'Anesthesiologie 43: 267-272.

47 Narchi P, Benhamou D, Fernandez H (1991) Intraperitoneal local anaesthetic for shoulder pain after day-case laparoscopy. Lancet 338: 1569-1570.

48 Goegler S, Blobner M, Busley R, Felber A, Jelen-Esselbom S (1993) Subphrenic catheter for postoperative analgesia after laparoscopic cholecystectomy. Anesthesiology 79: 26.

49 Hunter J, Staheli J, Oddsdottir M, Trus T (1995) Nitrous oxide pneumoperitoneum revisited. Is there a risk of combustion? Surgical Endoscopy 9: 501-504.

50 Jensen A, Prevdoros H, Kullman E, Andergerg B, Lennmarken C (1993) Peroperative nitrous does not influence recovery after laproscopic cholecystectomy. Acta Anaesthesiol Scand 37: 683-686.

51 Lipscomb G, Stovall T, Summitt R, Ling F (1993) The effect of nitrous oxide and carbon dioxide pneumoperitoneum on postlaparoscopy tubal ligation pain. J Gynecol Surg 9: 175-178.

52 Liu S, Hodgson P (2001) Local anaesthetics. Clinical anaesthesia 4: 49-69.

53 Lundeberg S (2012) Pharmacokinetic and pharmacodynamic aspects on opioid administration, morphine and ketobemidone, in the pediatric population. Karolinska Institutet pp: 1-53.

54 Choonara I, Mckay P, Hain R, Rane A (1989) Morphine metabolism in children. Br J Pharmacol 28: 599-604.

55 Choonara I, Lawrence A, Michalkiewicz A, Bowhay A, Ratcliffe J (1992) 
Morphine metabolism in neonates and infants. $\mathrm{Br} \mathrm{J}$ Clin Pharmaco 34: 434-437.

56 Svensson J, Rane A, Sawe J, Sjoqvist F (1982) Determination of morphine, morphine-3-glucuronide and (tentatively) morphine-6glucuronide in plasma and urine using ion-pair high performance liquid chromatography. J Chromatogr 230: 427-432.

57 Gong Q, Hedner J, Bjorkman R, Hedner T (1992) Morphine-3glucuronide may functionally antagonize morphine-6-glucuronide induced antinoception and ventilatory depression in the rat. Pain 48: 249-255.

58 Osborne R, Thompson P, Joel S (1992) The analgesic activity of morphine-6-glucuronide. Br J Clin Pharmacol 34: 130-113.

59 Mandal A (2016) Morphine Side Effects. UK: News Medical life science; http://www.news-medical.net/health/Morphine-SideEffects.aspx.

60 James M (1992) Clinical use of magnesium infusions in anesthesia. Anesth Analg 74: 129-136.

61 Feria M, Abad F, Sanchez A, Abreu P (1993) Magnesium sulphate injected subcutaneously suppresses autotomy in peripherally deafferented rats. Pain 53: 287-293.

62 Tramer M, Schneider J, Marti R, Rifat K (1996) Role of magnesium sulfate in postoperative analgesia. Anesthesiology 84: 340-347.

63 Iseri L, French JH (1984) Nature's physiologic calcium blocker. Am Heart J 108: 188-193.

64 Woolf C, Thompson S (1991) The induction and maintenance of central sensitization is dependent on $\mathrm{N}$-methyl-D-aspartic acid receptor activation; implications for the treatment of post-injury pain hypersensitivity states. Pain 44: 293-299.

65 Levaux Ch, Bonhomme V, Dewandre PY, Brichant JF, Hans P (2003) Effect of intraoperative magnesium sulphate on pain relief and patient comfort after major lumbar orthopaedic surgery. Anaesthesia 68: 131-135.

66 Koinig H, Wallner T, Marhofer P, Andel H, Horauf K, et al. (1998) Magnesium sulfate reduces intra- and postoperative analgesic requirements. Anesth Analg 87: 206-210.

67 Meaghan A, Gabriela K (2015) Actions of bupivacaine, a widely used local anesthetic, on NMDA receptor responses. The Journal of Neuroscience 35: 831-842.

68 Alexander J (1997) Pain after laparoscopy. Br J Anaesth 79:369-378.

69 Egan TM, Harman SJ, Doucette EJ, Normand SL, McLeod RS (1988) A randomized controlled trial to determine effectiveness of fascial Instillation of Bupivacaine in preventing respiratory complication after elective abdominal surgery. Surgery 104: 734-740.

70 Tong Y, Wu C, Bai C, Lee H, Liang H, et al. (2014) Effect of extraperitoneal bupivacaine analgesia in laparoscopic inguinal hernia repair: a metaanalysis of randomized controlled trials. Hernia 18: 177-183.

71 Kara H, Sahin N, Ulusan V, Aydogdu T (2002) Magnesium infusion reduces perioperative pain. Eur J Anaesthesiol 19: 52-56.

72 Bhatia A, Kashyap L, Pawar DK, Trikha A (2004) Effect of intraoperative magnesium infusion on perioperative analgesia in open cholecystectomy. J Clin Anesth 16: 262-265.

73 Spreng U (2011) Prevention of postoperative pain - A series of randomized clinical trials. University of Oslo.
74 Razavi S, Peyvandi H, Jam A, Safari F, Teymourian H, et al. (2015) Magnesium Versus Bupivacaine Instillation in Controlling Postoperative Pain in Inguinal Hernia Repair. Anesth Pain Med 5: 30643.

75 Chander R, Liddle D, Kaur B, Varghese M (2011) Wound Instillation with plain bupivacaine as compared with bupivacaine fentanyl mixture for postoperative pain relief after abdominal surgery. Anesthesia: Essays and Researches 5: 142-146.

76 Tverosky M, Cozcor C, Ayaiche M (1990) Postoperative pain relief after inguinal herniorraphies different types of Anaesthesia. Anesthesia Analgesia 70: 29-35.

77 Upadya M, Pushpavathi S, Rao Seetharam K (2015) Comparison of intra-peritoneal bupivacaine and intravenous paracetamol for postoperative pain relief after laparoscopic cholecystectomy. Anesthesia: Essays and Researches 9: 39-43.

78 Eldaba A, Amr Y, Sobhy R (2013) Effect of wound Instillation with bupivacaine or lower dose bupivacaine/magnesium versus placebo for postoperative analgesia after cesarean section. Anesthesia: Essays and Researches 7: 336-340.

79 Morrow GR (1984) The assessment of nausea and vomiting, past problems, current issues, and suggestion for future research. Cancer 53: 2267-2280.

80 Shoebi G, Sadegi M, Firozian M, Tabassomi M (2007) The additional effect of magnesium sulfate to lidocaine in spinal anesthesia forcesarean section. Int J Pharmacol 3: 425-427.

81 Mentes O, Harlak A (2008) Effect of intraoperative magnesium sulphate infusion on pain relief after laparoscopic cholecystectomy. Acta Anesthesiol Scand 52: 1353-1359.

82 Saadwy I, Kaki A (2010) Lidocaine vs. magnesium: effect on analgesia after laparoscopic cholecystectomy. Acta Anesthesiol Scand 54: 549-556.

83 Kesavan S (2010) Approapriate timing of administration of magnesium sulphate during spinal anesthesia to enhance postoperative analgesia. BJA 104: 89-93.

84 Lee D, Kwon I (2009) Magnesium sulphate has beneficial effects as an adjuvant during general anesthesia for caesarean section. BJA 103: 861-866.

85 Ray M, Bhattacharjee D (2010) Effect of clonidine and magnesium sulphate on anesthetic consumption, hemodynamics and postoperative recovery: a comparative study. Indian J Anesth pp: 54.

86 Scheinin B, Kellokumpu I, Lindgren L, Haglund C, Rosenberg P (1995) Effect of intraperitoneal bupivacaine on pain after laparoscopic cholecystectomy. Acta Anesthesiol Scand 39: 195-198.

87 Abdel-Raouf M, Liu, Amer H (2004) Postoperative analgesic effects of intraperitoneal NMDA receptor antagonists (ketamine and magnesium) in patients undergoing laparoscopic cholecystectomy. Engl J Anaesth 20: 107-111.

88 Allegri M, Clark MR, De Andres J, Jensen TS (2012) Acute and chronic pain: where we are and where we have to go. Minerva Anestesiol 78: 222-235.

89 Ayoglu H, Kradeniz U (2005) The analgesic effect of magnesium sulphate and ketamine in patients undergoing laparoscopic cholecystectomy. The Pain Clinic 17: 45-53. 
90 Jiranantarat V, Rushatamukayanunt W, Lert-akyamanee N, Sirijearanai R, Piromrat I, et al. (2002) Analgesic effect of intraperitoneal instillation of bupivacaine for postoperative pain after laparoscopic cholecystectomy. J Med Assoc Thai 85: S897-903.

91 Kara H, Sahin N, Ulusan V, Aydogdu T (2002) Magnesium infusion reduces perioperative pain. Eur J Anaesthesiol 19: 52-56.
92 Lee I, Kim S, Kong M, Lee M, Kim N, et al. (2001) Pain after laparoscopic cholecystectomy: the effect and timing of incisional and intraperitoneal bupivacaine. Can J Anaesth 48: 545-550.

93 Spittal MJ, Hunter SJ (1992) A comparison of bupivacaine instillation and inguinal field block for pain control after herniorrhaphy. Ann R Coll Surg Engl 74: 85-88. 